\title{
Malnutrition among children in the sahel region: causes, consequences and prevention
}

\author{
G.O. Ayenigbara \\ Science and technical education department, Adekunle ajasin University, Akungba - Akoko, Ondo State, Nigeria
}

Email address:

ayenigbarageorge7@yahoo.com

\section{To cite this article:}

G.O. Ayenigbara. Malnutrition Among Children in the Sahel Region: Causes, Consequences and Prevention. International Journal of Nutrition and Food Sciences. Vol. 2, No. 3, 2013, pp. 116-121. doi:10.11648/j.ijnfs.20130203.14

\begin{abstract}
Childhood period is a period of rapid growth. Research has shown that malnutrition delays growth, retards mental development and predisposes affected individuals to, and aggravates health problems. In view of these deleterious consequences, the author examined the causes and consequences of malnutrition among children in the Sahel region and thereafter suggested workable strategies for its prevention in those countries.
\end{abstract}

Keywords: Malnutrition, Obesity, Kwashiokor, Marasmus, Hypertension, Colostrum

\section{Introduction}

Nutrition has been defined by [10] as a branch science which deals with food, the nutrients and other substances therein, their action, interaction and balance in relation to health and disease; and the processes by which an organism ingests, digests, absorbs, transports, utilizes and excretes food substances. Nutrition goes beyond food consumption. It encompasses the social, economic, cultural and psychological factors relating to food production, food distribution, preservation, preparation and consumption.

Food is any substance, solid or liquid which when ingested, provides the necessary raw materials for the structure and function of life, thus enabling the body to carry out its life functions [4]. As a complex substance, food provides a variety of nutrient in the diet of an individual. No single food stuff, except perhaps the first breast milk (Colostrums), can provide a complete diet [4].

For an individual to get appropriate and adequate nutrients from food stuffs, one should take a balanced diet. Nutrients are the constituents of food which must be supplied to the body in suitable amounts. They include the carbohydrates, fats and oils, proteins, vitamins, minerals and water. When taken in adequate quantity, the nutrients, individually and collectively, are indispensable in ensuring the optimum health, growth and function of every individual.

When the diet is lacking in certain nutrients, the effects may include lack of strength, stunted growth, diseases, poor metabolism of other nutrients and low integrity of the nervous system. On the other hand, when some of the nutrients are excessively consumed obesity may result, with its attendant health problems. Therefore, a balance in the nutrients consumed must be struck through acceptable eating culture to prevent malnutrition.

Malnutrition is a pathological condition brought about by the inadequacy, or over consumption, of one or more of the essential nutrients necessary for survivals growth and reproduction, as well as productivity at work. There are different types of malnutrition of which the most important are Protein - Energy - Malnutrition (PEM), and deficiencies in critical micro-nutrients such as Vitamin A, Iron, Iodine and Zink. Another type of malnutrition is obesity, with inherent complications of hypertension, cardiovascular diseases and diabetes. These consequences occur as a result of over consumption of the wrong types of food and the adoption of sedentary lifestyle.

For the majority of children, the period of formal education is also a period of rapid growth. Research in many areas has conclusively shown that malnutrition delay growth [6], retards mental development and predisposes individuals to and/or aggravates health problems, particularly in children [4], [2]; [8], and [7]. It is in the light of these findings that this paper examined the causes and consequences of malnutrition and the preventive measures against malnutrition among children in the Sahel region 


\section{Causes of Malnutrition Among Children in the Sahel Region}

The causes of malnutrition are multi - factorial. The aetiology of malnutrition reflects what obtains in the society. Inadequate nutrition results from several biologic, sociocultural and economic aberrations among which are poverty, inadequate knowledge of nutrition, inadequate and unsafe water supply which predisposes individuals to diarrhea and water borne diseases [4]. Rapid urbanization and the migration of large numbers of young people in particular to the urban areas have reduced the agricultural labour force relative to the size of the domestic food market. Even so, domestic food production is much lower than it could be. Agriculture is carried out almost entirely by peasant farmers, using traditional techniques and implements. About 95 percent of total food production, according to [13], comes from small holding averaging about 2 hectares. Almost all farmers rely on shifting cultivation and manual land preparation, and only a small minority have access to inorganic fertilizer and improved seeds. Inadequate extension services and a weak rural credit system compound the constraint. Consequently, yields remain very low and crops have relatively low nutrients capacity compared with improved varieties.

Furthermore, agriculture is overwhelming rain - fed in the Sahel region, resulting in marked year - to - year fluctuations in food production, particularly for cereals. The countries irrigation potential is still only slightly tapped. Disease and pests problems also cause large crop losses. In addition, the rise of the oil sectors resulted in the relative neglect of the agricultural sector along with adverse exchange rate and price effects on domestic food production. The inadequate or insufficient distribution and marketing systems aggravate the shortfall in domestic food supply. This not only keeps farm gate prices low (to the benefit of middlemen), thereby reducing production incentives, but also prevents a significant part of the output from reaching consumers at the right time, price and quality. The poor marketing facilities tend to increase the spoilage of highly perishable food production, while further wastages results from insufficient methods of food processing and food preparation. Since children are also members of the larger society, they are not immune to what effects the society.

Specifically, malnutrition may be caused by these factors

\subsection{Poverty}

More often than not, people are malnourished not because food items are not available, but because there is no adequate income to purchase them [9]. Ever increasing cost of food items makes parents to provide their children with whatever diet that is available, irrespective of whether such diet is adequate nutritionally or not. As a result of poverty, many parents find it impossible to provide their children with balanced diets.

\subsection{Illiteracy}

Lack of education, inadequate or inappropriate education breeds illiterate or semi - illiterate individuals who easily succumbs to superstitions, taboos and irrational beliefs about some food items. For instance, it is believed that the big chunk of meat is for the head of the family, with the result that the child is fed with very starchy watery food (Pap), the adequacy of the food is often measured by the size of the stomach. When the child has a full stomach, the child is regarded as having been adequately fed, regardless of the quality and quantity of the nutrients contained in the diet.

\subsection{Poor Preservation, Distribution and Preparation of Food}

Poor food storage, distribution and preparation contribute very much to the problem of malnutrition in Nigeria. Due to poor communication and terrible road net work, there is a general misdistribution of the food that is available, to the extent that the fish produced at Calabar invariably never gets to Sokoto, and the chicken produced in Sokoto may never get to Lagos [4].

Moreover, most food crops produced are seasonal. Many families cannot afford to buy refrigerators and where refrigerators are available, electricity supply to operate them is erratic. Traditional methods of food preservation such as salting and drying are not reliable. As a result of poor food handling as explained above, it has been estimated that no less than $50 \%$ of the raw food produced in the Sahel region is lost before it gets to the dining table.

\subsection{Poor Family Set-Up}

Poor family set -up does not ensure proper spacing of children, and this may result in malnutrition. Family planning with adequate birth intervals is essential for proper growth and development of children, as it allows the mother enough time for full recovery after child birth. Where this does not occur, maternal malnutrition prior to or during pregnancy may lead to under weight babies. This condition may be compounded further after birth by insufficient food intake. When too many children are produced, and this is beyond the ability of the parents to feed adequately, it will definitely lead to malnutrition among other health problems.

\subsection{Inadequate Water Supply}

Inadequate water supply, a common feature in the Sahel region readily facilitates poor sanitary conditions which precipitate infections, with deleterious nutrition consequences. Infectious diseases, especially among children may contribute and precipitate malnutrition. Reference[4] observed that diarrhea diseases, measles and respiratory and other infections frequently result in negative protein and energy balances due to anorexia, vomiting, decreased absorption and catabolic processes. 


\subsection{Natural and Man Made Disasters}

Natural and man - made disaster such as wars, earthquakes, floods, prolonged droughts and forced migrations which readily lead to cyclic, sudden or prolonged food scarcities, can cause malnutrition among whole population by disrupting the process of food production, distribution, preservation, preparation and consumption. The current flood in Cameroon, Ghana and Nigeria; the military conflicts in Mali, Central African Republic and Nigeria and the drought in Niger Republic for example will negatively affect farming activities and ultimately result in malnutrition.

\subsection{Insufficient Food Production}

Insufficient food production, as a result of an everreducing number of hands on the farm, is an important cause of malnutrition. There is mass exodus of young able - bodied men and women from rural to urban areas in search of better jobs, particularly in the oil sector. Also, inadequate food production may be due to the inefficient methods of food production, such as the use of primitive tools, use of low yielding varieties of crops and a general lack of modern scientific method of farming.

\subsection{Political Factors}

The government at Federal, State and Local government levels pay lip service to food production. Instead, they embark on bogus projects at the detriment of food production in sufficient quantity for the populace. Rather than encourage local food production, they prefer importation of food from overseas countries. On arrival, some of these food items more often than not, have lost their nutritive values after such values have expired.

\subsection{Food Preparation and Consumption}

The choice of the food one takes depends, sometimes on availability, education and accepted preferences or principles. Method of preparation sometimes improve the quality of the food. At other times, there is an adverse effect. For example, fermentation of cereals increases the availability of a group of vitamins, where as exposure of chopped - up vegetables and fruits cooked loses Vitamin C group. Over washing of cereals and over milling makes for a poor quality food [8]. In some homes, certain food items are erroneously not considered food for certain physiological groups, yet these same food may nutritionally be what the group requires. For instance, meat, fish and eggs, in many parts of Africa, are not considered good food for children. In some parts, eggs and groundnut are forbidden for pregnant women.

\subsection{Diseases}

malnutrition among children may be caused by diseases. The effects of malnutrition and infection on the human body system and health according to [11] and [12] are synergistic, synergism is the joint action of agents such that their combined effect is greater than the algebraic sum of their individual effects. Malnutrition lowers resistance to infection, and infectious diseases tend to magnify an existing malnutrition. Infections decrease appetite and increase metabolic losses of nitrogen and other essential nutrients, during convalescence, the need for dietary protein is therefore great [4] and if this is not adequately supplied, malnutrition ensued. The simultaneous presence of malnutrition and infection results in an interaction with an enlarged effect that is more serious than would be expected if malnutrition or infection acted separately. Thus, infections are more severe in the poorly - nourished while the presence of an infection severely aggravates an existing malnutrition that has played a prominent part in its origin [4]

\section{Consequences of Malnutrition on Children in the Sahel Region}

Good nutrition is essential for health. Every individual requires adequate nutrition in quality and quantity for energy, body repair, for growth, for the maintenance of body temperature and for metabolic process. As for children, adequate nutrition is needed to perform all these functions. However, malnutrition has serious deleterious effects on the health of the children. Malnutrition lowers resistance to infections and infectious diseases and also magnifies existing malnutrition problems . Nutritional deficiency enhances the risk of acquired infection and when infection set in, the course and severity are greatly enhanced. So, a malnourished child cannot avail himself or herself the opportunity to succeed in school and be effective scholastically.

According to [4], malnutrition especially the protein energy malnutrition (PEM), produces progressive weight loss, weakness and apathy leading to further decreased food in-take and an exacerbation of malnutrition. Also, the metabolic effects of PEM can be super - imposed upon by any underlying disease process preventing early recovery from infection, surgery and injury, even in previously healthy person. Furthermore, the result of PEM may be an impairment of wound healing. In addition, long standing protein deficiency may lead to impaired immune mechanisms leading to increased wound infections, increased incidence of pneumonities and urinary tract infections and impaired responses to chemotherapy [4].

The brain is vulnerable during the initial spurt of growth. Inadequate nutrition before birth and in the first few years of life can seriously interfere with brain development and lead to such neurological and behavioural disorders as learning disabilities [5] among school children.

Malnourished children will become stunted in growth. Stunted growth affects academic performance. A study among school children in Ibadan by [3] found that heightfor-age was a good predictor of mental performance; with stunted children performing poorly on various scholastic aptitude tests. Wasting due to malnutrition was also correlated with poor scores [1]. 
Also, nutritional deficiencies, particularly in early childhood, can result in visual or hearing disabilities, or even in mental impairment. Hungry children are less able to concentrate in school, and malnutrition expose children to a higher risk of infection, resulting in more frequent illness and absence from school than in the case of well nourished children.

Moreover, if malnutrition is allowed to persist for a long time, it may degenerate into Kwashiokor, Marasmus and even Obesity with their attendant consequences. Kwashiokor, for example, may precipitate edema, growth retarda-

\begin{tabular}{l} 
In Infant and Children \\
\hline * Diminishing the ability to fight infection \\
*Impairs the immune system and increase risk of some infections \\
*Impair growth \\
*Increases chance of Infant/Child Mortality \\
*Heightens fatigue and apathy \\
* Hinders cognitive/metal development \\
* Reduces learning capacity
\end{tabular}

Adapted from Alade (2001) sustained approach to Nutrition in Africa 1999

In addition, nutritional deficiencies are other factors that contribute to high rates of mobility, mortality, and disability among children in Nigeria. Malnutrition in early life can have serious repercussion in later life. For example, women who were stunted in childhood are more prone to have low birth weight babies. Another example is the life long impact of certain serious micro-nutrient deficiencies, such as blindness in the case of iodine. For the majority of children, the period of former education is the period of rapid growth. Reference [6] has conclusively shown that malnutrition delay growth. Chronic malnutrition according to the expert can retard and diminish growth and result in undersized individuals.

\section{Prevention of Malnutrition Among Children}

Malnutrition is a problem affecting both the young and elderly. However, the consequences are more pronounced on the growing children. Since the aetiology of malnutrition was multi-factorial, its prevention should be multidimensional. Therefore the following measures should be taken to avert malnutrition generally, but with emphasis on children in the Sahel region.

\subsection{Poverty Reduction}

The Federal, State and Local Government should provide conducive political as well as socio-economic atmosphere that will enable all citizens to be gainfully employed so as to have means of livelihood. Prices of food stuff should be brought low, and within the purchasing power of every member of the society through a deliberate food pol tion, muscles wasting among others, while obesity is known to predispose individuals to hypertension and other cardiovascular diseases, diabetes, cancer, arthritis, difficulties in pregnancy and child birth later in life. Obesed people are usually clumsy. [7] observed that fat individuals are very prone to home accidents and are more often than not subjects of motor accident mortalities.

Nevertheless, some effects of malnutrition on health and economic status, as reported by [4] are presented below:

Some effects of malnutrition on health and Economic status:

* Increase risk of complication during pregnancy

* Increase risk of Spontaneous abortion, still birth, impaired fetal brain development and infant deaths

* Increase risk of death from spontaneous abortion, stress of labour, and delivery complication.

* Increases chance of producing low birth weight babies

* Reduces work productivity

* Increases risk of some infections, including HIV and reproductive tract

infections

*Results in more sick days and lost productivity.

icy, as it is done in many developed countries. Appropriate food policy may enhance and facilitate adequate food intake.

\subsection{Supplementary Feeding Programme}

Supplementary feeding may be undertaken to meet the anticipated needs of the at-risk populations. Such programmes, according to [8], may be entirely local or supported from International Aid. Food items such as skimmed milk, corn, soya, milk preparations, cereals and pulse of various kinds may be used in these programmes. Supplementary feeding programames are good, especially in time of catastrophes, such as during floods, famines, droughts, earthquakes or wars. Supplementary feeding may also be incorporated into the school health programmes for primary schools. In this case, mid day meals that will supplement what the pupils take at home should be introduced. The federal, State and Local Government should be encouraged to provide mid day meals for the pupils free of charge.

\subsection{Nutrition Education}

As part of general health education programme, nutrition education should be emphasized. Parents need to be educated on the need for and how to provide their children with balanced diets using locally available condiments. Nutrition education can be carried out through specially organized seminars for parents or presentations during Parents and teachers' Association (PTA) meeting.

\subsection{Health Education}

Health education is very crucial in curbing malnutrition among school children. Primary school pupils need to be educated on hygienic handing, preservation and consump- 
tion of food and the need to take balanced diet with plenty of fruits. Parents also require health education because of the need to provide their children with balanced diet and also to prevent infections. Food vendors and food handlers should also be health educated as they may serve as conduits of infections. Regular medical examinations should be factored into the health Education and made mandatory for food vendors and food handlers.

\subsection{Control of Infections}

There is the necessity to control infectious diseases among children through appropriate methods such as health education, instructions, immunization, regular medical examination, appraisal, isolation and referral. Infectious diseases, according to [4], act synergistically as contributing and precipitating factor in under nutrition.

\subsection{Early Diognosis and treatment}

There is the need for routine and periodic appraisal of the health of the children to detect those that show signs and symptoms of malnutrition such as Kwashiorkor, Marasmus, obesity etc. to this end, every teacher in the primary school should be suspicious of changes in their pupils. Pupils discovered to be suffering from malnutrition should be referred to the hospital for appropriate treatment. The teacher should do a follow up, and both parents and teachers should cooperate to ensure optimum health of their pupils.

\subsection{Family Planning}

When there are too many children who are closely spaced in the family, there may be the tendency for malnutrition to occur. Therefore, family planning education which provides for appropriate information on having children by choice, rather than by chance, with adequate spacing in between births, should be encouraged. Family planning may prevent maternal malnutrition prior to pregnancy; prevent underweight babies and insufficient diet for the children.

\subsection{Improvement in Agriculture}

To stem the tide of malnutrition among children, there should be an improvement in Agricultural practice, especially in the area of land use, better farm practices and better seed selection. There should be production of highyielding cereals e.g. lysine maize and high yielding protein cereals. The better storage of agricultural produce, especially of cereals, vegetables and tubers will help to cut down food losses by a substantial percentage and thereby lead to an increase in the available food supplies. Strategically located silos, as well as village storage of cereals and root crops, improved marketing and distribution of foods will provide some measure of incentive for greater food production effort.

\subsection{Fiscal Policy}

There should be a national policy that has objectives in the field of food production, food storage, processing, marketing, import and exports, pricing distribution, consumption, food legislation, health protection and promotion by means of education as well as control of disease. It must also make provision for the training of personnel for home management, extension education and provision for special feeding programmes.

\subsection{End to Wars}

The United National, African Union and the Economic Community of West African States (ECOWAS) should intensify their efforts to bring Inter-Communal, Civil and International Conflicts to and end in the Sahel region. Stable and democratic government should be installed in the region so that agricultural activities among others may not be disrupted.

\section{Refereences}

[1] Aina, T.A Etta, F.E; and Zeitlin, M.F. (1992). Child development and Nutrition in Nigeria: A Textbook for Educational, health and Social Service professionals Federal Ministry of Education and UNICEF Lagos

[2] Ajala, J.A. (2006). Understanding Food and Nutrition. Ibadan, may Best Publications

[3] Akimokun, O.O. (1989). The Impact of Nutrition on Intelligence Performance of School Age Children in Ibadan, Ph.D Thesis Department of Human Nutrition University of Ibadan, Ibadan.

[4] Alade, Ibukun Olu (2001), Public health Nutrition $\left(2^{\text {nd }}\right.$ ed.) Ilori, S.O.A. Fosco Venture press

[5] Begley, S. (1996), Your Child's Brain Newsweek, New York, 19 February

[6] Durojaiye, M.O.A. (1976), A New Introduction to Educational Psychology, Ibadan, Evans Brothers Limited.

[7] Fleck, H. (1976, In Introduction to Nutrition, $3^{\text {rd }}$ ed., New York, Macmillan Publishing co. Inc

[8] Lucas, A.O. and Gilles, H.M. (2003), A short Textbook of Preventive Medicine for the tropics. London, Holder and Stoughton.

[9] Pellet, P.I. (1983), Commentary: Changing Concept on World Malnutrition, Ecal. Ed. Nutr. 13

[10] Robinson, W.D. (1966), In proceedings, Western hemisphere Nutrition Congress, 1965, American Medical Association, Chicago, P. 206

[11] Scrimshaw, N.S. (1964), Ecological Factors in Nutritional Diseases Am J. Clin Nitri. 14:112-122.

[12] Scrimshaw, N.S. (1964), Causes of Malnutrition. In: G.H. Beaton, ed., 
[13] Nutrition, A Comprehensive Treatise, Academic Press, New York.
[14] UNICEF, (2001), Children's and Women's Rights in Nigeria: A Wake up call. National Planning Commission, Abuja, Nigeria. 